\title{
Orthographic Neighbours are not all Equal: Evidence using an Identification Technique
}

\author{
Manuel Perea \\ Facultat de Psicologia, Universitat de València, València, Spain
}

\begin{abstract}
The definition of orthographic neighbour (Coltheart et al., 1977) was analysed in two experiments using a variety of the three-field technique (Humphreys et al., 1988). With this technique, a clearly visible prime (in lower-case letters) is followed by a briefly presented upper-case word which is immediately masked. Pairs of five-letter neighbouring words were selected. Only orthographically related pairs that differed from the prime by the third letter (womenWOVEN) or the fourth letter (frost-FRONT) showed (inhibitory) relatedness effects compared with an unrelated word condition. The results suggest that models of visual word recognition should be modified to address the fact that some letter positions are more important than others.
\end{abstract}

\section{INTRODUCTION}

Current models of visual word recognition usually assume that, before word identification, a set of candidate units orthographically similar to the stimulus word (the so-called orthographic neighbours) are activated. Most studies have equated this candidate set with Coltheart, Davelaar, Jonasson and Besner's (1977) definition of an orthographic neighbour: any word that can be created by changing one letter of the stimulus word, preserving letter positions. For instance, band, send, said and sane are all orthographic neighbours of sand.

Coltheart's index is clearly a first approximation to the size of the candidate set. The first problem with this index is that a word's orthographic

Requests for reprints should be addressed to Manuel Perea, Àrea de Metodologia, Facultat de Psicologia, Av. Blasco Ibá ez 21,46010 València, Spain. E-mail: mperea@uv.es

This research was supported by grants PS/94-0193 from the Dirección General de Investigación Científica y Técnica and GV 2427/94 from the Programa de Investigación Cientifica y Desarrollo "Generalidad Valenciana". I would like to thank Ken Paap for help throughout the experiments and for use of his laboratory at New Mexico State University. I also thank Elaine Gilman for testing the subjects in Experiment 2. Finally, I also wish to acknowledge Dean Hooper and Arcadio Gotor for comments on an earlier draft of the manuscript. 
neighbours differ in frequency of usage. Assuming that the processes underlying visual word recognition imply competition between the word units activated in the cohort of candidates (Grainger, O'Regan, Jacobs \& Segui, 1989, 1992; Grainger \& Jacobs, 1996; McClellend \& Rumelhart, 1981), the selection process may be influenced by a word's more frequent neighbours. In fact, previous research has shown that words with higherfrequency neighbours are responded to more slowly than words with no higher-frequency neighbours in different tasks (lexical decision task, Carreiras, Perea \& Grainger, 1997; Grainger et al., 1989, 1992; Grainger \& Jacobs, 1996; Perea \& Pollatsek, in press; but see Forster \& Shen, 1996; Sears, Hino \& Lupker, 1995; identification tasks, Carreiras et al., 1997; Grainger \& Jacobs, 1996; Grainger \& Segui, 1990; eye-movement studies, Grainger et al., 1989; Perea \& Pollatsek, in press).

The second problem with Coltheart's definition is that it does not involve any differential weight in dependence with the letter mismatch between the orthographic neighbours. That is, both story and stock are higher-frequency neighbours of stork. Current models of visual word recognition also assume that all letter positions of a given word are equally activated (e.g. search model, Forster, 1976; interactive activation model, McClelland \& Rumelhart, 1981; activation-ve rification model, Paap, Newsome, McDonald \& Schvaneveldt, 1982; multiple read-out model, Grainger \& Jacobs, 1996). Nevertheless, that assumption was made basically for simplicity's sake. In the first version of the search model, Forster (1976) suggested that exterior letters-rather than interior letters-are used to access the subset of word candidates. Similarly, Rumelhart and McClelland (1982), Paap et al. (1982) and Grainger et al. (1992) also indicated that letter positions should play a part in visual word recognition.

In fact, there is some empirical evidence to suggest that not all orthographic neighbours are equally activated, in a seminal study on competitor units in visual word recognition. Havens and Foote (1963) suggested that a word's competitors should be of high frequency and differ from the target word only with respect to an interior letter. In an analysis of error data on a speeded identification task, Grainger and Segui (1990) suggested that the fact that a French word like bille is sometimes incorrectly reported as bible, but never as ville (which is also a high frequency neighbour of bille) can be taken to indicate that "neighbors differing by internal letters are more competitive than neighbors differing by the initial letter" (p. 196). Furthermore, in a lexical decision task with a single-presen tation paradigm, Grainger et al. (1992) found that the neighbourhood frequency effect was stronger for words that differ from a more frequent word by the fourth letter (e.g. speck because of its higher frequency neighbour speak) than for words that differ from a more frequent word by the second letter (carve because of curve). In addition, there is clear evidence in favour of the privileged role of 
word-initial and word-final information compared with word-medial information in different experimental tasks (e.g. Humphreys, Evett \& Quinlan, 1990; Jordan, 1990; McCusker, Gough \& Bias, 1981).

In the present study, a priming technique was used to enhance the effects of competitiveness among orthographic neighbours in visual word recognition. Specifically, the technique used in the study is the three-field technique (Humphreys, Besner, \& Quinlan, 1988), in which a clearly visible prime (in lower-case letters) is followed by a briefly presented upper-case word which is immediately masked, and the percentage of correct target identifications is measured. With this technique, when the prime and the target are identical, the magnitude of the inhibition effect relative to an unrelated word condition is rather robust (see Hochhaus \& Marohn, 1991; Humphreys et al., 1988; Park \& Kanwisher, 1994; Perea, 1993; Perea \& Gotor, 1994), which has been considered to be a variety of the repetition blindness effect (Bavelier, Prasada \& Segui, 1994; Hochhaus \& Marohn, 1991; Park \& Kanwisher, 1994).

Interestingly, Bavelier et al. (1994) found inhibitory effects with orthographic neighbours by using a rapid serial visual presentation (RSVP). Inhibitory effects from orthographically similar words tended to be smaller than the typical repetition blindness effect. However, Bavelier and colleagues did not manipulate the position of mismatch of the orthographic neighbours. Using the three-field technique, Perea and Gotor (1994) found stronger inhibitory effects for orthographically related words when the pairs differed by the third letter (lado-LAGO, side-LAKE) than when the pairs differed by the first letter (maiz-RAIZ, corn-ROOT). However, there was an obvious confounding in Perea and Gotor's study. The results could have been due to two different mechanisms: (1) left-to-right processing, so that initial letters provide more activation to the lexical level than final letters (e.g. Grainger et al., 1992), or (2) interior letters provide less activation than initial or final letters (Forster \& Davis, 1984; Grainger \& Segui, 1990; Havens \& Foote, 1963).

To summarise, the aim of this study was to analyse whether or not orthographic neighbourhood effects in five-letter words can be modulated by the position of the mismatch between primes and targets using the three-field technique. The position of mismatch was manipulated in two experiments: first, third and fifth letter in five-letter words (Experiment 1) and second and fourth letter (Experiment 2) in five-letter words. Experiment 1 was designed to analyse whether shared end-letters are more important than shared middle-letters, whereas Experiment 2 explored whether there is a serial readout of information for internal letters. To maximise the chance of obtaining an inhibitory effect of orthographic relatedness, related primes were always higher-frequency neighbours of the word targets (see Bavelier et al., 1994). Parallel models, such as the 
interactive activation model (McClelland \& Rumelhart, 1981) or the multiple read-out model (Grainger \& Jacobs, 1996), can simulate those inhibitory effects as a function of within-level inhibition among orthographically related pairs. Additionally, serial-search models, such as the activation-verification model (Paap et al., 1982), predict that highfrequency words inhibit or disrupt temporarily the processing of their lower-frequency neighbours (see Segui \& Grainger, 1990). However, neither of those models predicts a differential effect of the position of the mismatching letter, since all the letters provide a similar weight in the word-recognition process.

\section{EXPERIMENT 1}

If medial letters play a minor role in the selection process in visual word recognition compared with initial or final letters (as suggested by Grainger \& Segui, 1990; Havens \& Foote, 1963), orthographic relatedness effects should be greater when a medial letter mismatches. Furthermore, if there is a word-initial bias in the sublexical-to-lexical connections, the effects of orthographic relatedness should be stronger for words sharing word-medial information (and word-final information) than for words sharing wordinitial information.

\section{Methods}

Subjects. Thirty-eight psychology students at New Mexico State University participated in the experiment in exchange for course credit. All were native speakers of English.

Design and Stimuli. Seventy-two pairs of five-letter English words that differed by the first (e.g. alound-CLOUD), third (women-WOVEN) or fifth letter (grass-GRASP) were selected (see Appendix 1). All target words had only one higher-frequency neighbour (the prime word) and were extracted from low-density neighbourhoods. The mean frequency was 6.7 (range 1-24) per million (Kucera \& Francis, 1967) for the target words that differed from the prime by the first letter, 4.5 (range 1-18) for those that differed from the prime by the third letter, and 4.8 (range 0-23) for those that differed from the prime by the fifth letter. Unrelated word primes with no obvious semantic relation to their corresponding target (e.g. dressQUACK) were used as controls. Unrelated primes did not share any letter in the same position with their corresponding targets. Unrelated and related primes were matched for word frequency. In all pairs, primes were more frequent than their corresponding targets. Prime-target pairs were counterbalanced in two lists, so that no subject saw any prime or target more than once, but each subject received the six experimental conditions (12 pairs per condition). The font used for the stimuli was 12 point Courier. 
Procedure. Subjects were tested either singly or in groups of two or three in a quiet room. Presentation of the stimuli was controlled by Apple Macintosh Plus microcomputers. On each trial, the prime (always in lower-case letters) was presented for $500 \mathrm{msec}$ in the centre of the screen. Next, the target word (always in upper-case letters) was presented centred for $67 \mathrm{msec}$, being immediately masked by a sequence of five hash marks (\#\#\#\#) for $500 \mathrm{msec}$. Subjects were instructed to write down the upper-case word, even if in doubt, on a piece of paper. After that, subjects were to press the space bar to begin the next trial. Each subject received 12 practice trials before the 72 experimental trials. Stimulus presentation was randomised, with a different order for each subject. The whole session lasted approximately $10 \mathrm{~min}$.

\section{Results and Discussion}

The percentage of trials on which subjects reported correctly the target word in each condition was scored. The data were analysed in a $2 \times 2 \times 3$ design: group (list $1 v s$ list 2) $\times$ orthographic relatedness (related $v s$ unrelated) $\times$ position of mismatch (first, third or fifth letter). The group variable was included to extract the variance due to the counterbalancing procedure (see Pollatsek \& Well, 1995). Two analyses of variance were carried out, one using the subjects as a random factor $\left(F_{1}\right)$ and the other using the items as a random factor $\left(F_{2}\right)$. The percentage of correct target identifications in each experimental condition is shown in Table 1.

The effect of orthographic relatedness was statistically significant $\left[F_{1}(1,36)=14.37, P<0.001 ; F_{2}(1,66)=12.20, P<0.001\right]$; word targets preceded by an orthographically related prime were identified worse than those preceded by an unrelated word prime. The effect of position of mismatch was significant in the analysis by subjects $\left[F_{1}(2,72)=37.13\right.$, $\left.P<0.001 ; F_{2}(2,66)=3.11, P=0.051\right]$. More importantly, the interaction of position of mismatch and orthographic relatedness was significant in the analysis by subjects $\left[F_{1}(2,72)=3.88, P<0.03\right]$ and approached significance in

TABLE 1

Percentage of Correct Target Identifications on Word Targets in

Experiment 1

\begin{tabular}{lccc}
\hline & \multicolumn{3}{c}{ Position of Mismatch } \\
\cline { 2 - 4 } & First & Third & Fifth \\
\hline Related targets & 72 & 55 & 57 \\
Unrelated targets & 75 & 68 & 61 \\
R-U & -3 & -13 & -4 \\
\hline
\end{tabular}

Note: $\mathrm{R}-\mathrm{U}$ refers to the difference between related targets and unrelated targets. 
the analysis by items $\left[F_{2}(2,66)=3.12, P<0.051\right]$. The effects of orthographic relatedness were significant for pairs that differed by the third letter $\left[F_{1}(1,36)=17.16, P<0.001 ; F_{2}(1,66)=16.25, P<0.001\right]$ but not for pairs that differed by the first letter (both $F$ 's $<1$ ) or the fifth letter $\left[F_{1}(1,36)=2.48\right.$; $\left.F_{2}(1,66)=1.63\right]$. In addition, there were some differences between the unrelated targets as a function of position of mismatch (see Table 1). Post hoc comparisons on the unrelated targets using Tukey's HSD procedure showed significant difference $(P<0.05)$ between all three positions of mismatch in the analysis by subjects. However, the analysis by items did not reveal any significant differences among the three means. Since most of the experimental words were of very low frequency, the most plausible explanation of the differences in the by-subjects analysis is in terms of a lack of control of subjective familiarity for the word targets across conditions (see Forster \& Shen, 1996; Gernsbacher, 1984).

To summarise, inhibitory relatedness effects were only found for pairs that differed by a middle letter, and not for pairs that differed by the initial or final letter, which suggests that the relationship between orthographic neighbours may vary according to the position of the mismatching letter. In addition, the inhibitory effects did not appear to be due to any guessing effects in the three-field technique. For instance, it has been argued that subjects may be reluctant to say a related target word, especially in the case of the identical condition (see Hochhaus \& Marohn, 1991; Park \& Kanwisher, 1994). However, that possibility cannot be applied to the present experiment, since all priming conditions were interleaved in the same experiment but only one of them yielded significant effects (see Park \& Kanwisher, 1994, for a similar argument).

\section{EXPERIMENT 2}

The results of Experiment 1 do not rule out the existence of a word-initial bias in visual word recognition such as that found by Grainger et al. (1992) with a single-word paradigm. It might be argued that the failure to obtain significant relatedness effects for the initial and final letters might have been caused by the important role played by external letters in lexical access. For that reason, the position of mismatch was manipulated in two interior letters (second and fourth letter) for five-letter words.

\section{Methods}

Subjects. Thirty-six psychology students at New Mexico State University participated in the experiment in exchange for course credit. All were native speakers of English. None of them had taken part in Experiment 1. 
Design and Stimuli. Forty pairs of five-letter English words that differ by the second (e.g. colts-CULTS) or fourth letter (speak-SPECK) were selected (see Appendix 2). All target words had only one higher-frequency neighbour (the prime word) and were extracted from low-density neighbourhoods. The mean frequency was 4.6 (range 1-23) per million for the target words that differed from the related prime by the second letter and 5.4 (range 1-20) per million for those that differed from the related prime by the fourth letter. Unrelated word primes with no obvious semantic relation to the target word (e.g. human-SPECK) were used as controls. Unrelated and related prime were matched for word frequency. In all pairs, prime were more frequent than their corresponding targets. As in Experiment 1, prime-target pairs were counterbalanced in two lists, so that no subject saw any prime or target more than once, but each subject received the four experimental conditions (10 pairs per condition).

Procedure. The procedure was identical to that of Experiment 1.

\section{Results and Discussion}

The data for the word targets were analysed in a $2 \times 2 \times 2$ design: (group $($ subject $v s$ item $) \times$ orthographic relatedness (related $v s$ unrelated) $\times$ position of mismatch (second or fourth letter). The mean percentage of correct target identifications on target words is presented in Table 2.

The main effect of orthographic relatedness was significant $\left[F_{1}(1,34)=\right.$ $\left.6.81, P<0.02 ; F_{2}(1,36)=8.57, P<0.01\right]$; on average, targets preceded by orthographically related primes were identified worse than those preceded by unrelated prime ( $48 v s 55 \%$ ). The main effect of position of mismatch was not significant (both $F$ 's $<1$ ). The interaction between orthographic relatedness and position of mismatch was significant $\left[F_{1}(1,34)=12.25, P<\right.$ $\left.0.002 ; F_{2}(1,36)=8.60, P<0.006\right]$; the effect of orthographic relatedness was due to the pairs that differed by the fourth position $\left[F_{1}(1,34)=16.97, P<\right.$ $\left.0.001 ; F_{2}(1,36)=17.17, P<0.001\right]$, but not to the pairs that differed by the

TABLE 2

Percentage of Correct Target Identifications on Word Targets in

Experiment 2

\begin{tabular}{lcc}
\hline & \multicolumn{2}{c}{ Position of Mismatch } \\
\cline { 2 - 3 } & Second & Fourth \\
\hline Related targets & 51 & 45 \\
Unrelated targets & 51 & 59 \\
R-U & 0 & -14 \\
\hline
\end{tabular}

Note: $\mathrm{R}-\mathrm{U}$ refers to the difference between related targets and unrelated targets. 
second position (both $F$ 's $<1$ ). Like Experiment 1 the analysis by subjects revealed significant differences between the unrelated words in the two conditions of the factor position of mismatch $\left[F_{1}(1,34)=8.13, P<0.01\right]$. However, those differences might well have been due to the differential familiarity of some of the word targets, since the effect was far from significant in the analysis by items $\left[F_{2}(1,36)=0.97\right]$.

The results of this experiment are clear-cut: Higher-frequency orthographic neighbours that differ by the fourth letter appear to be more competitive than those that differ by the second letter.

\section{GENERAL DISCUSSION}

The main result of the present experiments is that not all orthographic neighbours should be given the same weight. Specifically, inhibitory effects from higher-frequency orthographic neighbours in five-letter words were found only when the prime and the target differed by the third or fourth letter (e.g. chair-CHOIR, speak-SPECK).

The results of Experiment 1 support the role of external letters in visual word recognition. In fact, the quality of information about letter positions is better at the end of the word than in internal letters because of lateral interference (e.g. Estes, Allmeyer, \& Reder 1976; Jordan, 1990). As a result, neighbours that differ from a lexical item by an interior letter are likely to be more interfering than a neighbour that differs on either the first or last letter of the word. ${ }^{1}$ A consequence of the previous finding is that the uptake of letter coding appears to operate in parallel (at least for relatively short words). Furthermore, Experiment 2 shows that the degree of relationship between neighbours in five-letter words is stronger for those words that differ by the third and fourth position, which stresses the existence of some left-to-right read-out of letter information.

There are several ways to modify the interactive activation model or its extensions (e.g. the multiple read-out model, Grainger \& Jacobs, 1996) so that these models might accommodate the present results. Grainger (1992; Grainger et al., 1992) suggested two possibilities: (1) assigning different weights to the letter-word excitation parameter as a function of the letter position, or (2) using different values of the maximum letter activation for the different letter positions. For instance, we might use maximum letter activation values of $1.0,0.9,0.7,0.6$ and 0.9 (the default value is 1.0 ) for the letter positions in five-letter words or letter-word excitation values of 0.070 ,

\footnotetext{
${ }^{1}$ Similarly, when the pairs in Experiment 1 were used in a lexical decision task using the masked priming technique (Forster \& Davis, 1984), the latency data showed inhibitory effects only for the pairs that differed by an internal letter (Perea \& Rosa, submitted). Nonetheless, the error data showed an inhibitory relatedness effect that did not interact with the position of mismatch.
} 
$0.065,0.054,0.052$ and 0.068 (the default value for five-letter words is 0.060 ). This way, it will take longer for the recognition process for words with a higher-frequency neighbour in a middle letter than in an exterior letter. Of course, the question is whether the modification of those parameters might harm the model's ability to account for other word recognition phenomena.

Serial-search models such as the activation-verification model (Paap et al., 1982) can also capture the basic results with a few assumptions. The activation-verification model uses empirically determined confusion matrices to generate activation levels to the letter level and the word level. Appropriate transformations of the matrix can be performed so that external letters would provide more activation than internal letters (see Paap et al., 1982, p. 577). As a consequence, words that share external letters would be more likely to enter the candidate set than those that share internal letters, and thus orthographic priming effects for five-letter words are more likely to occur for those pairs that differ by the third or the fourth letter.

Nonetheless, visual factors also play a role in visual word recognition. Models must take into account that the quality of information is greatest for the fixated letter (e.g. see O'Regan, 1990). For instance, Grainger et al. (1992) found smaller inhibitory neighbourhood frequency effects for the French word chope (which has one higher-frequency neighbour, the French word chose) when the subjects were initially fixating the fourth letter (i.e. the disambiguating letter) than when they were fixating the second letter. That implies that the values for the letter positions not only depend on "structural" factors (e.g. greater lateral inhibition for internal letters) but also on the letter the subject is looking at (see Grainger, 1992).

An important question when we analyse orthographic priming effect is whether or not the obtained effects may have been influenced by phonological effects. For that reason, a post hoc analysis was conducted to disentangle orthographic and phonological priming effects. Phonological neighbours were defined in the same way as orthographic neighbours: Two words are phonological neighbours when they differ by just one phoneme (i.e. horde and horse would be phonological neighbours, whereas timed and timid would not). The means per condition are shown in Table 3. As can be seen in this table, the effects are virtually the same for pairs that were both orthographic and phonological neighbours and for pairs that were just orthographic neighbours. A similar result was obtained by Evett and Humphreys (1981) with the four-field technique (in which both the prime and the target were presented very briefly and masked). Furthermore, Bavelier et al. (1994) also found inhibitory relatedness effects for orthographic neighbours when phonology was controlled. The failure to obtain an effect due to phonology has been interpreted in terms of slower automatic access based on a phonemic code compared with automatic access based on orthographic information (see Evett \& Humphreys, 1981). 
TABLE 3

Relatedness Effects (Difference between Related Targets and Unrelated Targets) as a Function of Position of Mismatch and Phonological Relation (Numbers in Parentheses Refer to the Number of Items in each Condition)

\begin{tabular}{lrlrl}
\hline & \multicolumn{4}{c}{ Type of Relation between Prime and Target } \\
\cline { 2 - 4 } Position of Mismatch & \multicolumn{2}{c}{ Phonological } & Only Orthographic \\
\hline First letter & -4 & $(16)$ & 0 & $(8)$ \\
Second letter & 1 & $(9)$ & -1 & $(11)$ \\
Third letter & -12 & $(10)$ & -14 & $(14)$ \\
Fourth letter & -14 & $(10)$ & -14 & $(10)$ \\
Fifth letter & -3 & $(5)$ & -4 & $(19)$ \\
\hline
\end{tabular}

To summarise, future research should take into account no only whether a given word has higher-frequency neighbours, but also the relative letter positions of those higher-frequency neighbours. The fact that previous studies have not controlled for this factor may have led, in part, to the controversial results in the literature on neighbourhood frequency effects (e.g. see Carreiras et al., 1997; Grainger et al., 1989, 1992; Grainger \& Jacobs, 1996; Grainger \& Segui, 1990; Huntsman \& Lima, 1996 vs Forster \& Shen, 1996; Sears et al., 1995). For instance, Perea and Pollatsek (in press) found significant neighbourhood frequency effects by comparing words with no higher-frequency neighbours and words whose higher-frequency neighbours differed from the target word by an interior letter.

Manuscript received February 1997 Revised manuscript received July 1997

\section{REFERENCES}

Bavelier, D., Prasada, S., \& Segui, J. (1994). Repetition blindness between words: Nature of the orthographic and phonological representations involved. Journal of Experimental Psychology: Learning, Memory and Cognition, 20, 1437-1455.

Carreiras, M., Perea, M., \& Grainger, J. (1997). Effects of orthographic neighbourhood in visual word recognition: Cross-task comparisons. Journal of Experimental Psychology: Learning, Memory and Cognition, 23, 857-871.

Coltheart, M., Davelaar, E., Jonasson, J.F., \& Besner, D. (1977). Access to the internal lexicon. In S. Dornic (Ed.), Attention and performance VI. Hillsdale, NJ: Lawrence Erlbaum associates Inc.

Estes, W.K., Allmeyer, D.H., \& Reder, S.M. (1976). Serial position functions of letter identification at brief and extended exposure durations. Perception and Psychophysics, 19, $1-15$.

Evett, L.J., \& Humphreys, G.W. (1981). The use of abstract graphemic information in lexical access. Quarterly Journal of Experimental Psychology, 33A, 325-350.

Forster, K.I. (1976). Accessing the mental lexicon. In R.J. Wales \& E.W. Walker (Eds), New approaches to language mechanisms. Amsterdam: North-Holland. 
Forster, K.I., \& Davis, C. (1984). Repetition priming and frequency attenuation in lexical access. Journal of Experimental Psychology: Learning, Memory, and Cognition, 10, 680-698.

Forster, K.I., \& Shen, D. (1996). No enemies in the neighborhood: Absence of inhibitory neighborhood effects in lexical decision and semantic categorization. Journal of Experimental Psychology: Learning, Memory and Cognition, 22, 696-713.

Gernsbacher, M.A. (1984). Resolving 20 years of inconsistent interactions between lexical familiarity and orthography, concreteness, and polysemy. Journal of Experimental Psychology: General, 113, 256-281.

Grainger, J. (1992). Orthographic neighborhoods and visual word recognition. In R. Frost \& L. Katz (Eds), Orthography, morphology, and meaning. Elsevier: Amsterdam.

Grainger, J., \& Jacobs, A.M. (1996). Orthographic processing in visual word recognition: A multiple read-out model. Psychological Review, 103, 518-565.

Grainger, J., \& Segui, J. (1990). Neighborhood frequency effects in visual word recognition: A comparison of lexical decision and masked identification latencies. Perception and Psychophysics, 47, 191-198.

Grainger, J., O'Regan, J.K., Jacobs, A.M., \& Segui, J. (1989). On the role of competing word units in visual word recognition: The neighborhood frequency effect. Perception and Psychophysics , 45, 189-195.

Grainger, J., O’Regan, J.K., Jacobs, A.M., \& Segui, J. (1992). Neighborhood frequency effects and letter visibility in visual word recognition. Perception and Psychophysics, 51, 49-56.

Havens, L.L., \& Foote, W.E. (1963). The effect of competition on visual duration thresholds and its independence of stimulus frequency. Journal of Experimental Psychology, 65, 6-11.

Hochhaus, L., \& Marohn, K. (1991). Repetition blindness depends on perceptual capture and token individuation failure. Journal of Experimental Psychology: Human Perception and Performance, 17, 422-432.

Humphreys, G.W., Besner, D., \& Quinlan, P.T. (1988). Event perception and the word repetition effect. Journal of Experimental Psychology: General, 117, 51-67.

Humphreys, G.W., Evett, L.J., \& Quinlan, P.T. (1990). Orthographic processing in visual word identification. Cognitive Psychology, 22, 517-560.

Huntsman, L.A., \& Lima, S.D. (1996). Orthographic neighborhood structure and lexical access. Journal of Psycholinguistic Research, 25, 417-429.

Jordan, T.R. (1990). Presenting words without interior letters: Superiority over singles letters and influence of postmark boundaries. Journal of Experimental Psychology: Human Perception and Performance, 16, 891-909.

Kučera, H., \& Francis, W.N. (1967). Computational analysis of present-day American English. Providence, RI: Brown University Press.

McClelland, J.L., \& Rumelhart, D.E. (1981). An interactive activation model of context effects in letter perception: Part 1. An account of basic findings. Psychological Review, 88 , 375-407.

McCusker, L.X., Gough, P.B., \& Bias, R.G. (1981). Word recognition inside out and outside in. Journal of Experimental Psychology: Human Perception and Performance, 7, 538-551.

O'Regan, J.K. (1990). Eye movements in reading. In E. Kowler (Ed.), Eye movements and their role in visual and cognitive processes. Amsterdam: Elsevier.

Paap, K.R., Newsome, S.L., McDonald, J.E., \& Schvaneveldt, R.W. (1982). An activationverification model for letter and word recognition: The word superiority effect. Psychological Review, 89, 573-594.

Park, J., \& Kanwisher, N. (1994). Determinants of repetition blindness. Journal of Experimental Psychology: Human Perception and Performance, 20, 500-519.

Perea, M. (1993). Influencia de los factores de vecindad sobre el acceso léxico: Análisis experimentales y de simulación. Unpublished doctoral dissertation, Universitat de València. 
Perea, M., \& Rosa, E. (submitted). Los vecinos ortográficos no son iguales: Evidencia con la técnica de presentación enmascarada del estímulo-se al.

Perea, M., \& Gotor, A. (1994) Las palabras vecinas deben ponderarse: Evidencia mediante la ceguera perceptual. Cognitiva, 6, 123-132.

Perea, M., \& Pollatsek, A. (in press). The effects of neighborhood frequency in reading and lexical decision. Journal of Experimental Psychology: Human Perception and Performance.

Pollatsek, A., \& Well, A. (1995). On the use of counterbalanced designs in cognitive research: A suggestion for a better and more powerful analysis. Journal of Experimental Psychology: Learning, Memory and Cognition, 21, 785-794.

Rumelhart, D.E., \& McClelland, J.L. (1982). An interactive activation model of context effects in letter perception: Part 2. The contextual enhancement effect and some tests and extensions of the model. Psychological Review, 89, 60-94.

Sears, C.R., Hino, Y., \& Lupker, S.J. (1995). Neighbourhood frequency and neighbourhood size effects in visual word recognition. Journal of Experimental Psychology: Human Perception and Performance, 21, 876-900.

Segui, J. \& Grainger, J. (1990). Priming word recognition with orthographic neighbors: Effects of relative prime-target frequency. Journal of Experimental Psychology: Human Perception and Performance, 16, 65-76. 


\section{APPENDIX 1}

Related word pairs in Experiment 1

\begin{tabular}{|c|c|}
\hline Prime-Target Pairs & Prime-Target Pairs \\
\hline CLOUD-ALOUD & PILOT-PIVOT \\
\hline MORAL-CORAL & PRONE-PRUNE \\
\hline LEMON-DEMON & PURSE-PULSE \\
\hline LODGE-DODGE & QUICK-QUACK \\
\hline HONOR-DONOR & RAPID-RABID \\
\hline OTHER-ETHER & SEATS-SECTS \\
\hline TERMS-GERMS & SOLAR-SONAR \\
\hline BRIEF-GRIEF & STARS-STIRS \\
\hline MOIST-HOIST & TUMOR-TUTOR \\
\hline DANCE-LANCE & VAPOR-VALOR \\
\hline TROOP-DROOP & VINES-VICES \\
\hline PIECE-NIECE & VIOLA-VILLA \\
\hline FORMS-NORMS & WOMEN-WOVEN \\
\hline ALIVE-OLIVE & ANGER-ANGEL \\
\hline SWING-OWING & ASKED-ASKEW \\
\hline RATIO-PATIO & BRAVE-BRAVO \\
\hline CAUSE-PAUSE & BUTTS-BUTTE \\
\hline BONDS-PONDS & CIVIL-CIVIC \\
\hline GUEST-QUEST & TUBES-TUBER \\
\hline DEBUT-REBUT & COLOR-COLON \\
\hline VOGUE-ROGUE & FORGE-FORGO \\
\hline MOTOR-ROTOR & GRASS-GRASP \\
\hline HAPPY-SAPPY & GRAVE-GRAVY \\
\hline FOGGY-SOGGY & IDIOM-IDIOT \\
\hline CHIEF-THIEF & IRONY-IRONS \\
\hline TRAPS-WRAPS & RIVER-RIVET \\
\hline ANGLE-ANKLE & LATER-LATEX \\
\hline APPLY-APTLY & LIMBS-LIMBO \\
\hline ARGON-ARSON & LUNGS-LUNGE \\
\hline THING-THONG & MEDIA-MEDIC \\
\hline CHAIR-CHOIR & QUEEN-QUEER \\
\hline CREPT-CRYPT & RADIO-RADII \\
\hline DRAFT-DRIFT & REACH-REACT \\
\hline DUNES-DUKES & SCOUT-SCOUR \\
\hline EXPEL-EXCEL & SERVE-SERVO \\
\hline FEEDS-FEUDS & SIRED-SIREN \\
\hline LABEL-LAPEL & SMELL-SMELT \\
\hline LIONS-LIENS & UNTIL-UNTIE \\
\hline NOVEL-NOBEL & UPPER-UPPED \\
\hline
\end{tabular}




\section{APPENDIX 2}

Related word pairs in Experiment 2

\begin{tabular}{ll}
\hline Prime-Target Pairs & Prime-Target Pairs \\
\hline GRANT-GIANT & ALIVE-ALIKE \\
START-SMART & CHART-CHANT \\
PORCH-PERCH & DRUGS-DRUMS \\
BUGGY-BAGGY & SPEAK-SPECK \\
COLTS-CULTS & BURST-BURNT \\
SEEDS-SHEDS & FRONT-FROST \\
ABUSE-AMUSE & TIMED-TIMID \\
CURVE-CARVE & BRIDE-BRIBE \\
FORCE-FARCE & FIELD-FIEND \\
TASKS-TUSKS & SHALL-SHAWL \\
LABEL-LIBEL & TAXES-TAXIS \\
CLOAK-CROAK & TRAPS-TRAYS \\
MYTHS-MOTHS & VEINS-VEILS \\
SOLOS-SILOS & ALIEN-ALIGN \\
SHYLY-SLYLY & INERT-INEPT \\
SKIES-SPIES & HORSE-HORDE \\
ROOTS-RIOTS & FLINT-FLIRT \\
DEALS-DIALS & GAUGE-GAUZE \\
LARKS-LURKS & LEAKY-LEAFY \\
OPENS-OVENS & ROADS-ROARS \\
\hline
\end{tabular}

